\title{
Organogénesis a partir de ápices meristemáticos y discos caulinares de Aloe vera $\mathrm{L}$.
}

\section{Organogenesis in meristems and cauline disc of Aloe vera $\mathrm{L}$.}

\author{
Yuri Albarrán Ruiz \\ José Constantino Pacheco Maldonado ${ }^{\mathrm{b}}$ \\ Leidy Yanira Rache Cardenal ${ }^{*}$
}

Fecha de Recepción: 15.09.18

Fecha de Aceptación: 08.05.19

DOI: 10.19053/01217488.v10.n2.2019.9809

\begin{abstract}
Resumen
Aloe vera L. ha sido utilizada como planta medicinal y ornamental, por lo que ha adquirido gran importancia comercial; sin embargo, presenta una desventaja reproductiva en condiciones naturales que limita el abastecimiento de la demanda mundial. El objetivo del estudio fue evaluar el desarrollo de procesos organogénicos a partir de ápices meristemáticos y discos caulinares. Se emplearon como explantes, ápices meristemáticos y discos caulinares cultivados en medio Murashige y Skoog, suplementado con distintos reguladores de crecimiento. Se cuantificó el porcentaje de inducción callogénica y caulogénica. Los brotes regenerados fueron micropropagados en medio suplementado con $2 \mathrm{mg} \mathrm{L}^{-1}$ de BA y $0,1 \mathrm{mg} \mathrm{L}^{-1}$ de ANA y el enraizamiento fue ensayado bajo condiciones in vitro y ex vitro. El porcentaje más alto $(100 \%)$ de callogénesis en ápices meristemáticos se cuantificó en presencia de 0,5 y $1 \mathrm{mg} \mathrm{L}^{-1}$ de 2,4-D y $3 \mathrm{mg} \mathrm{L}^{-1} \mathrm{de}$ ANA y en discos caulinares en presencia de $0,5 \mathrm{mg} \mathrm{L}^{-1}$ de 2,4-D con $12.5 \%$. Durante la caulogénesis, el promedio más alto de brotes/explante $(1,1)$ se cuantificó en ápices meristemáticos en presencia de $5 \mathrm{mg} \mathrm{L}^{-1}$ de ANA; mientras que en discos caulinares se observó (1,3 brotes/explante), en presencia de $0,25 \mathrm{mg} \mathrm{L}^{-1}$ de 2,4-D. Después del segundo ciclo de micropropagación el promedio de brotes/explante desarrollados aumentó a 8,8. El mayor porcentaje $(75,3 \%)$ de brotes enraizados se cuantificó en condiciones in vitro. En conclusión, el explante primario más aconsejable para iniciar procesos organogénicos en $A$. vera fue ápices meristemáticos cultivados en medio con $5,0 \mathrm{mg} \mathrm{L}^{-1}$ de ANA.
\end{abstract}

Palabras clave: callos, cultivo in vitro, reguladores de crecimiento.

a Bióloga. Corporación autónoma regional de Chivor, Corpochivor, Garagoa-Boyacá-Colombia.

b Ph.D. Laboratorio de Cultivo de Tejidos Vegetales BIOPLASMA-UPTC. Escuela de Ciencias Biológicas, Facultad de Ciencias. Universidad Pedagógica y Tecnológica de Colombia, sede Central, Tunja-BoyacáColombia.

c Dra. Ciencias Biológicas. Universidad de los Andes, Bogotá-Colombia.

* Autor de correspondencia: yuloal1@hotmail.com. 


\begin{abstract}
Aloe vera $\mathrm{L}$. has been used as a medicinal plant and ornamental, so that this plant has acquired great commercial importance. However, $A$. vera $\mathrm{L}$. has a reproductive disadvantage under natural conditions limiting supply of world demand. The objective of this study was evaluated process organogenesis development from meristematic tip and cauline discs. Meristematic tip and cauline discs were used as explants and cultured on Murashige and Skoog medium supplemented with different growth regulators. The percentage of organogenic and callogenic induction was quantified. Regenerated shoots were micropropagated on medium supplemented with $2 \mathrm{mg} \mathrm{L}^{-1} \mathrm{BA}$ and $0.1 \mathrm{mg} \mathrm{L}^{-1} \mathrm{NAA}$, and rooting was tested under in vitro and ex vitro conditions. Highest percentage of callus formation in meristematic tip was quantified in presence of 0.5 and $1 \mathrm{mg} \mathrm{L}^{-1} 2,4-\mathrm{D}$ and $3 \mathrm{mg} \mathrm{L}^{-1} \mathrm{NAA}$ and in cauline disks in presence of $0.5 \mathrm{mg} \mathrm{L}^{-1}$ of 2,4-D. During caulogenesis, highest average number of shoots per explant (1.1) was quantified from meristematic tip in presence of $5 \mathrm{mg} \mathrm{L}^{-1} \mathrm{NAA}$, while in cauline disk (1.3 shoots/explant) were quantified in presence $0.25 \mathrm{mg} \mathrm{L}^{-1} 2,4-\mathrm{D}$. After micropropagation cycle second, the average number of shoots per explant increased to 8.8 . The highest percentage $(75.3 \%)$ of rooted shoots was quantified in vitro conditions. In conclusion, the primary explant more desirable to initiate organogenic processes in $A$. vera was meristems cultured in medium with $5.0 \mathrm{mg} \mathrm{L}^{-1} \mathrm{NAA}$.
\end{abstract}

Key words: callus, in vitro culture, growth regulators

\section{INTRODUCCIÓN}

Aloe vera L., pertenece a las Aloaceae, posee cualidades medicinales, cosméticas y sobresale entre las más de 390 especies botánicas del género Aloe [1, 2]. Ha sido utilizada desde la antigüedad como planta medicinal y valorada por sus propiedades curativas y uso ornamental [3].

El uso de esta planta en la elaboración de múltiples productos farmacéuticos, alimenticios y cosmetológicos, es atribuido a los metabolitos que posee [4], esto la ha convertido en la variedad más apreciada mundialmente [1] y de gran importancia comercial, provocando una amplia demanda de su cultivo.

Asimismo, la sábila constituye una alternativa de producción para las zonas áridas y semiáridas del mundo [5]; sin embargo, en condiciones naturales la propagación de Aloe es considerablemente lenta [6]. Sexualmente sus semillas presentan alta esterilidad masculina $\mathrm{y}$, asexualmente, el número de brotes axilares que produce cada planta es bajo y estacional $[7,4]$, pues la multiplicación tradicional es por separación de brotes o hijos que salen en la base de la planta, proceso que requiere un periodo de 20 meses para la producción de aproximadamente cuatro brotes por cada planta [5], lo que dificulta el abastecimiento de esta materia prima a nivel comercial, generando grandes limitaciones para suplir los mercados y satisfacer las demandas del producto [2].
Estas condiciones han generado la necesidad de explorar en nuevos campos como la biotecnología vegetal y la posible utilización del cultivo de tejidos vegetales in vitro, específicamente el proceso de organogénesis, mediante el cual es posible solucionar problemas como los mencionados anteriormente, de una manera eficiente y segura, con la finalidad de obtener mayores tasas de proliferación y la utilización de nuevos tejidos somáticos para inducir el desarrollo de yemas o de meristemos directamente a partir de explantes o a partir de callos [8]; además de permitir el estudio de las respuestas morfogénicas inducidas por reguladores de crecimiento en diferentes tipos de explantes y la secuencia de eventos ocurridos durante la formación y desarrollo de órganos adventicios.

El desarrollo de procesos organogénicos en A. vera ha sido analizado en diferentes estudios $[9,10,11,12,13]$. Seran y Ahmad, [2] utilizaron TDZ para la propagación clonal in vitro $\mathrm{y}$ producción masiva de plantas de Aloe. En este estudio se evaluó el efecto de algunos reguladores de crecimiento y el tipo de explante sobre el desarrollo in vitro de procesos organogénicos en A. vera.

\section{MATERIALES Y MÉTODOS}

Material vegetal de partida. Se recolectaron hijuelos vegetativos de aproximadamente 12 $\mathrm{cm}$ de longitud, de tres plantas productivas 
seleccionadas por sus características fenotípicas y buenas condiciones fitosanitarias, localizadas en un cultivo comercial del municipio de Santa Sofía, Boyacá. Los hijuelos se envolvieron en papel periódico y se mantuvieron en ambiente seco.

Condiciones generales de cultivo in vitro. El medio utilizado en todos los ensayos fue MS [14]. El pH de los medios fue ajustado a $5.8 \mathrm{con}$ $\mathrm{NaOH}$ ó $\mathrm{HCl}(0.5-1.0 \mathrm{~N})$ y se esterilizaron en autoclave a $121{ }^{\circ} \mathrm{C}$ y 15 psi de presión durante 20 minutos. Durante la fase de establecimiento de los cultivos, los explantes fueron cultivados en frascos de vidrio de $15 \mathrm{cc}$, con alícuotas de $7 \mathrm{ml} \mathrm{de}$ medio. Para las fases de inducción organogénica, micropropagación y enraizamiento in vitro, los explantes fueron cultivados en recipientes de vidrio de $100 \mathrm{cc}$, con alícuotas de $20 \mathrm{ml}$ de medio. Las condiciones del cuarto de crecimiento fueron: luz continua $\left(70-80 \mu \mathrm{mol} . \mathrm{m}^{2} / \mathrm{s}\right)$ suministrada por tubos fluorescentes de Sylvania luz día $(75 \mathrm{~W})$ y temperatura de $23 \pm 1{ }^{\circ} \mathrm{C}$.

Asepsia de explantes. En el Laboratorio de cultivo de tejidos vegetales BIOPLASMA, de la Universidad Pedagógica y Tecnológica de Colombia, Tunja - Boyacá, se tomaron los hijuelos y se les eliminó el sistema radical y las hojas más externas, reduciéndolos a rebrotes de 3-4 cm, los cuales fueron sometidos al siguiente protocolo de asepsia superficial: un enjuague con agua corriente; luego, en cámara de flujo laminar, se enjaguaron con agua destilada + Tween 20 (Merck) $(0.25 \mathrm{ml} / 100 \mathrm{ml})$ durante 5 minutos; posteriormente los rebrotes fueron sumergidos en etanol al $70 \%$ durante 5 minutos, seguido por una inmersión en solución de hipoclorito de sodio $(\mathrm{NaOCl})$ al 2,62\% (v/v) durante 15 ó 20 minutos. Finalmente, los rebrotes se enjaguaron tres veces consecutivas con agua destilada estéril.

Establecimiento de cultivos. Para inducir la respuesta callogénica y organogénica se evaluaron dos tipos de explantes primarios: ápices meristemáticos y discos caulinares tomados de los rebrotes superficialmente asépticos. Se cultivaron 10 discos caulinares y 10 ápices meristemáticos por cada tratamiento, para un total de 350 explantes sembrados. Los explantes fueron obtenidos mediante la eliminación de las hojas externas del rebrote al igual que la hoja acompañante del meristemo apical. El ápice meristemático fue escindido con una aguja hipodérmica estéril, mientras que los discos caulinares fueron tomados de la región subsiguiente al ápice meristemático con un grosor aproximado a $3 \mathrm{~mm}$. Los explantes se cultivaron y mantuvieron durante 90 días en medio con distintos reguladores de crecimiento escogidos según investigaciones reportadas por distintos autores (tabla 1), con transferencia de los explantes a medio fresco cada 30 días. Para reducir la exudación de fenoles y evitar el efecto nocivo de éstos al ser secretados al medio, se le adicionó $0,1 \mathrm{mg} \mathrm{L}^{-1}$ de ácido p-aminobenzoico al medio de cultivo.

Tabla 1. Reguladores de crecimiento y explantes utilizados para inducción de procesos organogénicos.

\begin{tabular}{|c|c|c|c|c|c|c|c|c|c|}
\hline \multirow[t]{2}{*}{ Tto } & \multirow[t]{2}{*}{$\begin{array}{l}\text { Reguladores de } \\
\text { crecimiento }\end{array}$} & \multirow[t]{2}{*}{$\begin{array}{l}\text { Concentración } \\
\left(\mathbf{m g ~ L ^ { - 1 } )}\right.\end{array}$} & \multicolumn{2}{|c|}{ Tipo de explante } & \multirow[t]{2}{*}{ Tto } & \multirow[t]{2}{*}{$\begin{array}{l}\text { Reguladores de } \\
\text { crecimiento }\end{array}$} & \multirow[t]{2}{*}{$\begin{array}{l}\text { Concentración } \\
\left(\mathrm{mg} \mathrm{L}^{-1}\right)\end{array}$} & \multicolumn{2}{|c|}{$\begin{array}{l}\text { Tipo de } \\
\text { explante }\end{array}$} \\
\hline & & & $\mathbf{A M}$ & DC & & & & $\mathbf{A M}$ & DC \\
\hline 1 & Sin reguladores & - & $\mathrm{x}$ & $\mathrm{x}$ & 20 & \multirow{2}{*}{ TDZ } & 0,5 & $\mathrm{X}$ & \\
\hline 2 & \multirow{3}{*}{ 2,4-D } & 0,25 & $\mathrm{X}$ & $\mathrm{X}$ & 21 & & 1,0 & $X$ & \\
\hline 3 & & 0,5 & $\mathrm{X}$ & $\mathrm{X}$ & 22 & \multirow[t]{2}{*}{$\mathrm{BA}$} & 3,0 & $\mathrm{X}$ & \\
\hline 4 & & 1,0 & $\mathrm{X}$ & $\mathrm{X}$ & 23 & & 5,0 & $\mathrm{X}$ & \\
\hline 5 & \multirow{5}{*}{ AIB } & 1,0 & $\mathrm{X}$ & & 24 & \multirow{2}{*}{ Kin } & 3,0 & $\mathrm{X}$ & \\
\hline 6 & & 3,0 & $\mathrm{X}$ & & 25 & & 5,0 & $\mathrm{X}$ & \\
\hline 7 & & 5,0 & & $\mathrm{x}$ & 26 & \multirow{2}{*}{ 2,iP } & 3,0 & $\mathrm{X}$ & \\
\hline 8 & & 7,0 & $\mathrm{X}$ & $\mathrm{x}$ & 27 & & 5,0 & $\mathrm{X}$ & \\
\hline 9 & & 10,0 & & $\mathrm{x}$ & 28 & $\mathrm{AIB}+\mathrm{Kin}$ & $1,0+5,0$ & & $\mathrm{X}$ \\
\hline
\end{tabular}




\begin{tabular}{|c|c|c|c|c|c|c|c|c|}
\hline 10 & & 1,0 & $\mathrm{X}$ & & 29 & 2,4-D+Kin & $0,25+5,0$ & $\mathrm{X}$ \\
\hline 11 & & 3,0 & $\mathrm{X}$ & & 30 & $2,4-\mathrm{D}+\mathrm{BA}$ & $0,25+2,0$ & $\mathrm{X}$ \\
\hline 12 & AIA & 5,0 & & $x$ & & & & \\
\hline 13 & & 7,0 & $\mathrm{X}$ & $\mathrm{x}$ & & & & \\
\hline 14 & & 10,0 & & $\mathrm{x}$ & & & & \\
\hline 15 & ANA & 1,0 & $\mathrm{X}$ & & & & & \\
\hline 16 & & 3,0 & $\mathrm{X}$ & & & & & \\
\hline 17 & & 5,0 & $\mathrm{X}$ & $\mathrm{x}$ & & & & \\
\hline 18 & & 7,0 & & $\mathrm{x}$ & & & & \\
\hline 19 & & 10,0 & & $\mathrm{x}$ & & & & \\
\hline
\end{tabular}

(2,4-D) Ácido 2,4 diclorofenoxiacético, (AIB) ácido indol-butírico, (AIA) ácido 3-indol-acético, (ANA) ácido $\alpha$-naftalenacético, (TDZ) N-fenil N-1,2,3-tidiazol-5-ilurea, (BA) 6-bencilaminopurina, (Kin) Kinetina y (2-iP) 2-isopenteniladenina. AM: Ápices meristemáticos, DC: Discos caulinares.

Trascurridos 45 días a partir del establecimiento del cultivo in vitro, se cuantificó el porcentaje de las respuestas morfológicas evidenciadas (rizogénesis, callogénesis). El porcentaje de caulogénesis y el promedio de brotes/explante regenerados a partir de los callos obtenidos, se cuantificó a los 90 días de la siembra.

Histología: Para identificar la respuesta organogénica en relación con la organización celular durante el proceso de formación de yemas adventicias a partir de callos, se realizaron observaciones microscópicas de cortes histológicos. Callos compactos de 90 días de cultivo, en diferente estado del proceso de formación de yemas, fueron fijados en carnoy durante 8 días, luego se deshidrataron progresivamente con etanol a 50,60, 70, 80, 90, 95, 98\% dejando actuar 3 horas cada uno; posteriormente, los callos fueron transferidos a isopropanol durante 3 horas y acetona absoluta durante 1 hora. Los tejidos fueron aclarados con xilol, durante 4 horas; finalmente, se incluyeron en parafina. Los cortes, de $20 \mu \mathrm{m}$ de espesor, se realizaron utilizando un micrótomo giratorio. $\mathrm{La}$ tinción de los tejidos se realizó con safranina y fast-green y safranina y eosina [8]. Los cortes se observaron y fotografiaron con ayuda de un microscopio Nikon eclipse E100, con objetivo de 4X y cámara Canon A480 de 10 mega pixeles.

Proliferación de brotes regenerados. Los brotes obtenidos de los procesos organogénicos indirectos, fueron individualizados, cultivados y mantenidos en medio con $2 \mathrm{mg} \mathrm{L}^{-1}$ de BA y $0,1 \mathrm{mg} \mathrm{L}^{-1}$ de ANA (reguladores de crecimiento $\mathrm{y}$ concentraciones determinadas en ensayos realizados previamente por integrantes del grupo, quienes registraron una media de regeneración de brotes de 3,2). A los brotes iniciales se les realizó un corte transversal a $2 \mathrm{~cm}$ de la base y un corte longitudinal procurando escindir el meristemo apical; luego se transfirieron al mismo medio. Después de 45 días de cultivo (ciclo vegetativo), los explantes fueron transferidos a medio fresco hasta completar dos ciclos consecutivos de cultivo (90 días). Se cultivaron 30 explantes, distribuidos en 6 frascos. Durante cada ciclo se determinó el promedio de brotes/explante y la longitud de los brotes.

Enraizamiento ex vitro $\boldsymbol{e}$ in vitro. Los explantes utilizados para enraizamiento ex vitro e in vitro, fueron brotes de $4-5 \mathrm{~cm}$ de longitud individuales, obtenidos del segundo ciclo de proliferación.

Para el enraizamiento ex vitro, los brotes fueron sembrados en sustrato compuesto por tierra, cascarilla de arroz, humus, capote y arena en proporciones $2: 1: 1: 1: 1 / 2$ respectivamente (el cual fue establecido en ensayos previos realizados en el grupo Bioplasma-UPTC), contenido en vasos plásticos de $40 \mathrm{cc}$, y colocados en condiciones de invernadero ( $75-85 \%$ de humedad relativa, temperatura media diurna $18^{\circ} \mathrm{C}$ y nocturna $12^{\circ} \mathrm{C}$ ). Se sembraron 100 brotes y se regaron por nebulización cada 24 horas, durante 16 segundos. 
Luego de 60 días en el sustrato, se determinó porcentaje de plántulas enraizadas, longitud y número de raíces desarrolladas por explante.

Para enraizamiento in vitro, los brotes se transfirieron a medio con $0,05 \mathrm{mg} \mathrm{L}^{-1}$ de ANA (regulador de crecimiento y concentración determinada en ensayos previos realizados por el grupo de investigación), se cultivaron 100 brotes y después de 20 días de cultivo, se cuantificaron las mismas variables que para enraizamiento ex vitro.

Aclimatización. Plántulas de $6 \mathrm{~cm}$ provenientes de brotes enraizados in vitro, se enjuagaron con agua corriente, se sembraron $\mathrm{y}$ mantuvieron en el mismo sustrato $\mathrm{y}$ condiciones utilizadas para enraizamiento ex vitro. Trascurridos tres meses en invernadero, se cuantificó el porcentaje de plántulas viables que reactivaron su crecimiento.

Análisis estadístico. Las variables número y longitud de raíces desarrolladas de los ensayos de enraizamiento ex vitro e in vitro y respuesta caulogénica fueron analizados mediante análisis de varianza (ANOVA), con un nivel de confiabilidad del 95\%. Para los factores que resultaron estadísticamente significativos se realizó la prueba DHS (Diferencia honestamente significativa) de Tukey $(\mathrm{p} \leq 0,05)$, utilizando el programa estadístico STATGRAPHICS Centurion XV.

\section{RESULTADOS}

Asepsia de explantes. El procedimiento de asepsia superficial utilizando $\mathrm{NaOCl}$ al 2,62\% durante 20 minutos fue efectivo, obteniéndose 98,9\% de explantes asépticos, mientras que al disminuir el tiempo de exposición a 15 minutos, el porcentaje de explantes asépticos disminuyó a $54.71 \%$.

Establecimiento de cultivos. Se evidenció que las respuestas morfogénicas fueron diferentes de acuerdo con el tipo de explante y el regulador adicionado al medio. El 41,2\% de ápices meristemáticos y el 44,1\% de discos caulinares presentaron respuesta callogénica; en tanto que un $40,3 \%$ de ápices meristemáticos y un $5,8 \%$ de discos caulinares presentaron rizogénesis. El desarrollo caulogénico adventicio observado en los diferentes tratamientos fue de $17,2 \%$ (figura 1 ).

En los cultivos de ápices meristemáticos se registró $100 \%$ de explantes con raíces en presencia de $1 \mathrm{mg} \mathrm{L}^{-1}$ de AIB y en 1 y $3 \mathrm{mg} \mathrm{L}^{-1} \mathrm{de}$ ANA. No se observó desarrollo de raíces en presencia de BA, 2-iP, Kin $\left(5 \mathrm{mg} \mathrm{L}^{-1}\right)$ y 2,4-D $\left(0,5\right.$ y $\left.1 \mathrm{mg} \mathrm{L}^{-1}\right)$. En presencia de Kin, BA $\left(5,0 \mathrm{mg} \mathrm{L}^{-1}\right)$, TDZ $(0,5$ $\left.\mathrm{mg} \mathrm{L} \mathrm{L}^{-1}\right)$, AIA ( 1 y $\left.3 \mathrm{mg} \mathrm{L}^{-1}\right)$ y AIB $\left(1 \mathrm{mg} \mathrm{L}^{-1}\right)$ se cuantificó $100 \%$ de plántulas desarrolladas (tabla 2). No se observó ninguna respuesta morfogénica en el tratamiento sin reguladores de crecimiento.

El mayor porcentaje de explantes con respuesta callogénica se evidenció en los tratamientos con auxinas, comparado con los de citoquininas. Entre las auxinas utilizadas, la que estimuló en mayor proporción $(100 \%)$ la formación de callo en ápices meristemáticos fue 2,4-D $(0,5$ y $1,0 \mathrm{mg}$ $\mathrm{L}^{-1}$ ), y ANA (3 $\mathrm{mg} \mathrm{L}^{-1}$ ) (tabla 2 ). De otro lado, el análisis de varianza para la variable desarrollo caulogénico a partir de ápices meristemáticos (P: 0,5798), no mostró diferencias estadísticamente significativas (tabla 2; figura 2).

Respecto a los discos caulinares al igual como en ápices meristemáticos, no se evidenció desarrollo de respuestas morfogénicas en el tratamiento testigo (sin reguladores de crecimiento), mientras que se cuantificó el mayor porcentaje de explantes con desarrollo de raíces (44,4\%) en presencia de $7 \mathrm{mg} \mathrm{L}^{-1}$ de AIB; en los demás tratamientos no se observó desarrollo rizogénico excepto en AIB (10 $\left.\mathrm{mg} \mathrm{L}^{-1}\right)$ y $\mathrm{AIA} \mathrm{(5,}$ 7 y $10 \mathrm{mg} \mathrm{L}^{-1}$, tabla 2).

Las mayores respuestas callogénicas (90 y $88,8 \%$ ) a partir de discos caulinares, se cuantificaron en medio con $0,5 \mathrm{mg} \mathrm{L}^{-1}$ de $2,4-\mathrm{D}$ (T2) y $7 \mathrm{mg} \mathrm{L}^{-1}$ de AIA (T12), respectivamente. Con AIB más Kin y con 5 y $10 \mathrm{mg} \mathrm{L}^{-1}$ de AIB no se evidenció callogénesis (tabla 2). Sin embargo, el desarrollo de plántulas a partir de este tipo de explante fue nulo en todos los tratamientos. La respuesta caulogénica de discos caulinares no presentó diferencias estadísticamente significativas, según el análisis de varianza (P: 0,2162 , tabla 2). 

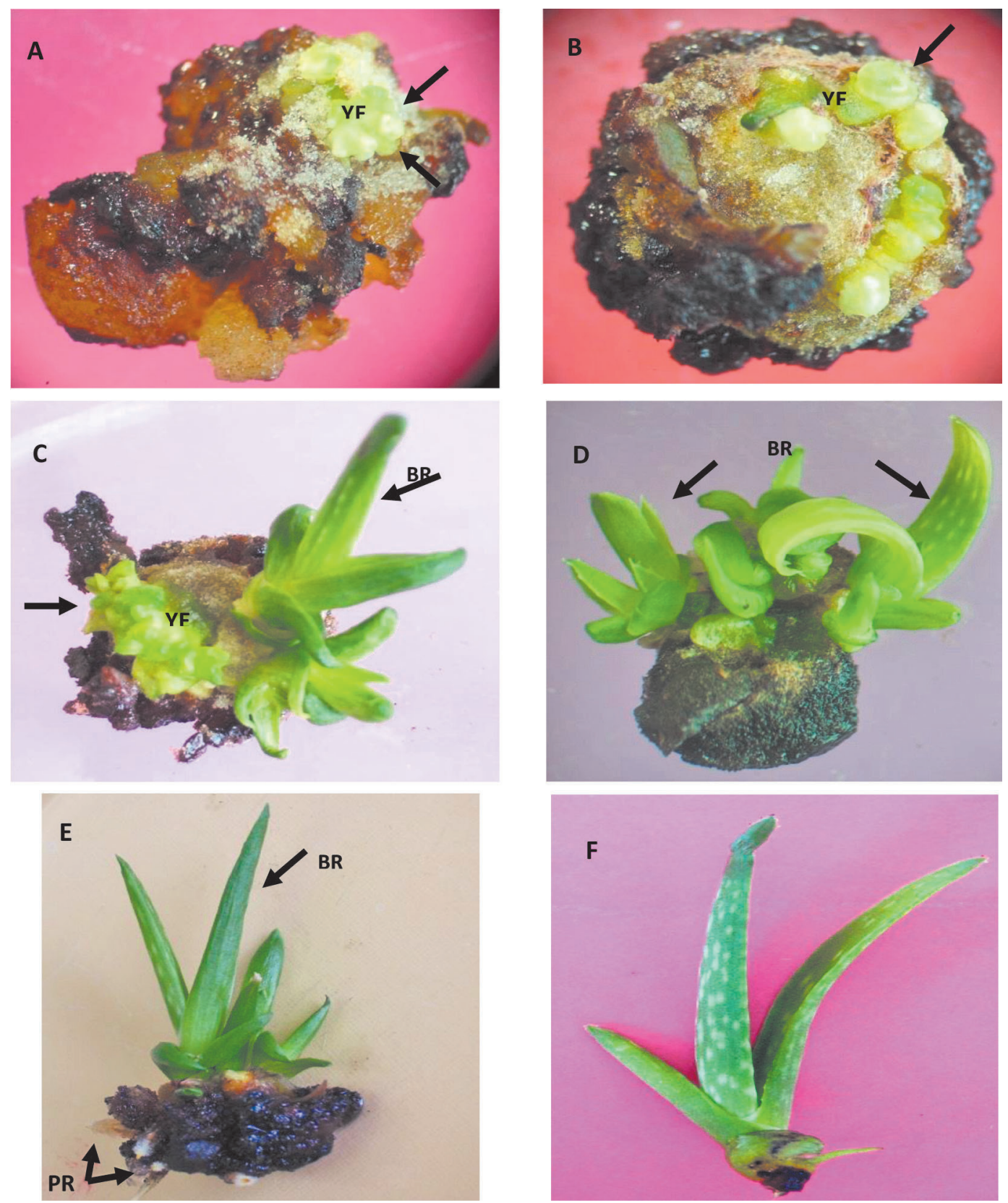

Figura 1. Caulogénesis adventicia indirecta en ápices meristemáticos y discos caulinares. A) Callo friable, B) Callo compacto, ambos con yemas adventicias en desarrollo. C) Callo compacto formado a partir de disco caulinar, D) Callo compacto, ambos con yemas y brotes desarrollados. E) Callo friable formado a partir de ápice meristemático con brotes en desarrollo. F) Brote desarrollado e individualizado. YE: yemas en desarrollo; BR: brotes regenerados. PR: primordios radiculares. Fuente: Autores.

Tabla 2. Respuesta morfogénica de ápices meristemáticos (A.M) y discos caulinares (D.C) cultivados en presencia de diferentes reguladores de crecimiento.

\begin{tabular}{|c|c|c|c|c|c|c|c|c|c|c|}
\hline \multirow{3}{*}{ Tto. } & \multirow{3}{*}{$\begin{array}{l}\text { Regulador } \\
\left(\mathrm{mg} \mathrm{L}^{-1}\right)\end{array}$} & \multirow{2}{*}{\multicolumn{2}{|c|}{$\begin{array}{c}\text { Rizogénesis } \\
(\%)\end{array}$}} & \multirow{2}{*}{\multicolumn{2}{|c|}{$\begin{array}{c}\text { Callogénesis } \\
(\%)\end{array}$}} & \multirow{3}{*}{$\begin{array}{c}\begin{array}{c}\text { Pl. } \\
\text { des. }\end{array} \\
(\%) \\
\text { A.M }\end{array}$} & \multicolumn{4}{|c|}{ Caulogénesis } \\
\hline & & & & & & & \multicolumn{2}{|c|}{$(\%)$} & \multicolumn{2}{|c|}{$\bar{x} \mathbf{B r} / \mathbf{E}$} \\
\hline & & A.M & D.C & A.M & D.C & & A.M & D.C & A.M & D.C \\
\hline 1 & Sin reguladores & 0 & 0 & 0 & 0 & 0 & 0 & 0 & 0 & $0 \pm 0,0$ \\
\hline 2 & $2,4-\mathrm{D}(0,25)$ & 26,6 & 0 & 86,6 & 50 & 6,6 & 0 & 12,5 & 0 & $1,3 \pm 0,7$ \\
\hline
\end{tabular}




\begin{tabular}{|c|c|c|c|}
\hline 3 & $2,4-\mathrm{D}(0,5)$ & 0 & 0 \\
\hline 4 & $2,4-\mathrm{D}(1,0)$ & 0 & 0 \\
\hline 5 & AIB $(1,0)$ & 100 & - \\
\hline 6 & $\operatorname{AIB}(3,0)$ & 50 & - \\
\hline 7 & $\operatorname{AIB}(5,0)$ & - & 0 \\
\hline 8 & $\operatorname{AIB}(7,0)$ & 50 & 44,4 \\
\hline 9 & $\operatorname{AIB}(10,0)$ & - & 10 \\
\hline 10 & $\operatorname{AIA}(1,0)$ & 75 & - \\
\hline 11 & $\operatorname{AIA}(3,0)$ & 75 & - \\
\hline 12 & $\operatorname{AIA}(5,0)$ & - & 14.2 \\
\hline 13 & $\operatorname{AIA}(7,0)$ & 90 & 11.1 \\
\hline 14 & $\operatorname{AIA}(10,0)$ & - & 11,1 \\
\hline 15 & $\operatorname{ANA}(1,0)$ & 100 & - \\
\hline 16 & ANA $(3,0)$ & 100 & - \\
\hline 17 & $\operatorname{ANA}(5,0)$ & 41,6 & 0 \\
\hline 18 & $\operatorname{ANA}(7,0)$ & - & 0 \\
\hline 19 & ANA $(10,0)$ & - & 0 \\
\hline 20 & $\operatorname{TDZ}(0,5)$ & 25 & - \\
\hline 21 & $\operatorname{TDZ}(1,0)$ & 0 & - \\
\hline 22 & $\mathrm{BA}(3,0)$ & 0 & - \\
\hline 23 & $\mathrm{BA}(5,0)$ & 0 & - \\
\hline 24 & $\operatorname{Kin}(3,0)$ & 25 & - \\
\hline 25 & $\operatorname{Kin}(5,0)$ & 0 & - \\
\hline 26 & $2, \mathrm{PP}(3,0)$ & 0 & - \\
\hline 27 & $2, \mathrm{iP}(5,0)$ & 0 & - \\
\hline 28 & $\operatorname{AIB}(1,0)+\operatorname{Kin}(5,0)$ & - & 0 \\
\hline 29 & $2,4-\mathrm{D}(0,25)+\operatorname{Kin}(5,0)$ & - & 0 \\
\hline 30 & $2,4-\mathrm{D}(0,25)+\mathrm{BA}(2,0)$ & - & 0 \\
\hline
\end{tabular}

\begin{tabular}{|c|c|c|}
\hline 100 & 90 & 40 \\
\hline 100 & 60 & 50 \\
\hline 0 & - & 100 \\
\hline 25 & - & 75 \\
\hline- & 0 & - \\
\hline 8,33 & 44,4 & 0 \\
\hline- & 0 & - \\
\hline 25 & - & 100 \\
\hline 50 & - & 100 \\
\hline- & 14,2 & - \\
\hline 20 & 88,8 & 0 \\
\hline- & 66,6 & - \\
\hline 50 & - & 50 \\
\hline 100 & - & 50 \\
\hline 91,6 & 66,6 & 0 \\
\hline- & 22,2 & - \\
\hline- & 66,6 & - \\
\hline 0 & - & 100 \\
\hline 0 & - & 25 \\
\hline 0 & - & 75 \\
\hline 0 & - & 100 \\
\hline 0 & - & 100 \\
\hline 0 & - & 100 \\
\hline 0 & - & 75 \\
\hline 8,3 & - & 0 \\
\hline- & 0 & - \\
\hline- & 62,5 & - \\
\hline - & 30 & - \\
\hline
\end{tabular}

\begin{tabular}{|c|c|c|c|}
\hline 0 & 0 & 0 & $0 \pm 0,0$ \\
\hline 0 & 0 & 0 & $0 \pm 0,0$ \\
\hline 0 & - & 0 & - \\
\hline 0 & - & 0 & - \\
\hline- & 0 & - & $0 \pm 0,0$ \\
\hline 8,3 & 0 & $0,6 \pm 0,5$ & $0 \pm 0,0$ \\
\hline- & 0 & - & $0 \pm 0,0$ \\
\hline 0 & - & 0 & - \\
\hline 0 & - & 0 & - \\
\hline- & 0 & - & $0 \pm 0,0$ \\
\hline 0 & 0 & 0 & $0 \pm 0,0$ \\
\hline- & 0 & - & $0 \pm 0,0$ \\
\hline 0 & - & 0 & - \\
\hline 0 & - & 0 & - \\
\hline 8,3 & 11,1 & $1,1 \pm 0,7$ & $1 \pm 0,8$ \\
\hline- & 0 & - & $0 \pm 0,0$ \\
\hline- & 0 & - & $0 \pm 0,0$ \\
\hline 0 & - & 0 & - \\
\hline 0 & - & 0 & - \\
\hline 0 & - & 0 & - \\
\hline 0 & - & 0 & - \\
\hline 0 & - & 0 & - \\
\hline 0 & - & 0 & - \\
\hline 0 & - & 0 & - \\
\hline 8,3 & - & $0,8 \pm 0,8$ & - \\
\hline- & 0 & - & $0 \pm 0,0$ \\
\hline- & 0 & - & $0 \pm 0,0$ \\
\hline- & 0 & - & $0 \pm 0,0$ \\
\hline
\end{tabular}

PI. des: plántulas desarrolladas; $\overline{\times} \mathbf{B r} / \mathbf{E}$ : promedio de brotes por explante. \pm Desviación estándar. N.S.: No significativo.

Histología. El análisis de la secuencia histológica a través de las diferentes etapas del desarrollo organogénico, permitió identificar centros de división con proliferación celular activa (figura 2A) que dan origen a células meristemáticas y que se caracterizan por presentar mayor grado de tinción en comparación con las no meristemáticas; son células pequeñas y con núcleos predominantes. 

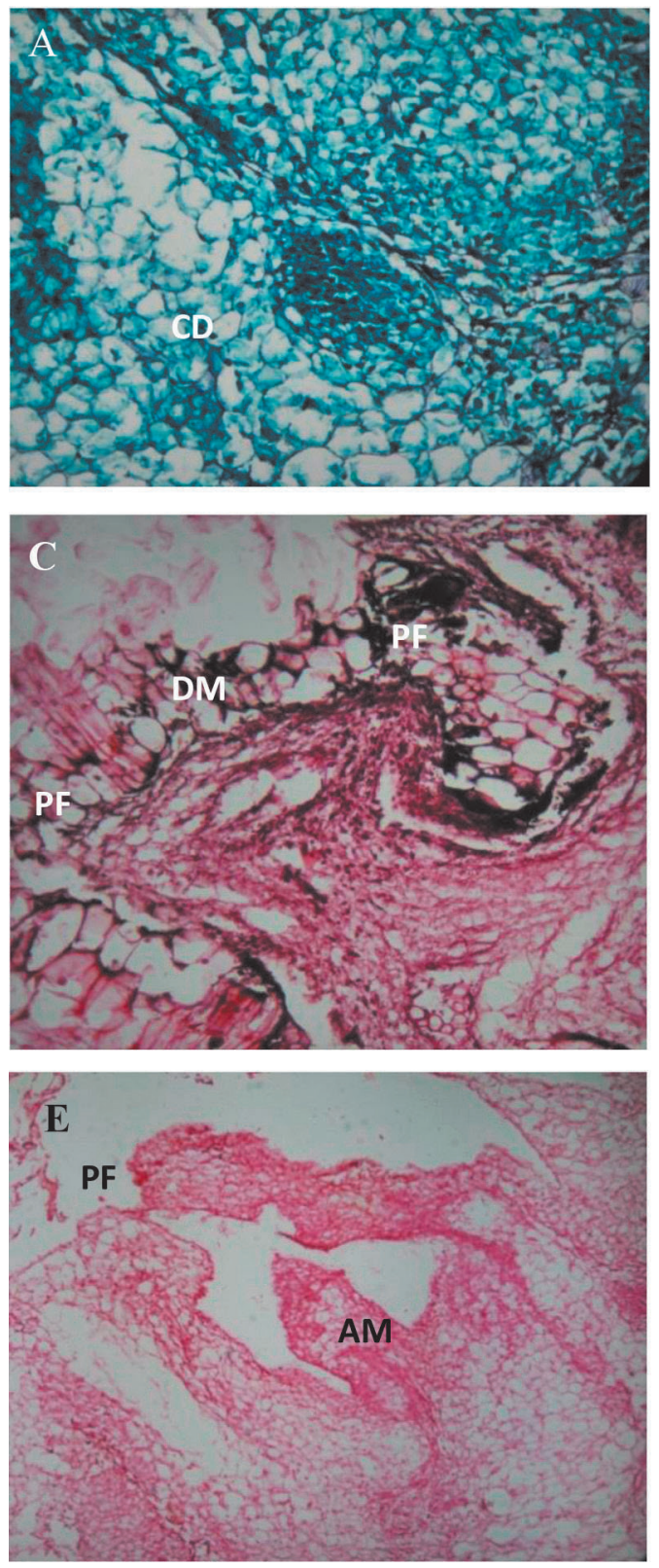
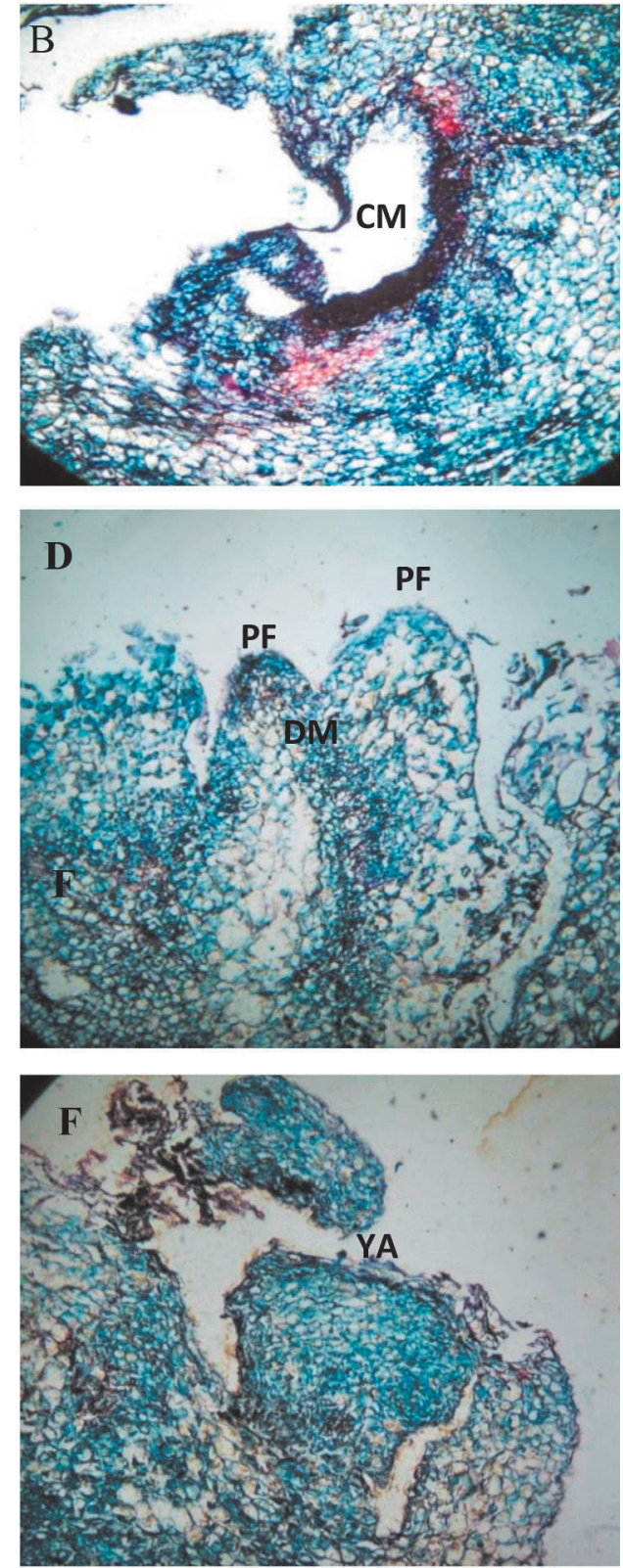

Figura 2. Cortes histológicos de diferentes etapas durante la formación de yemas en $A$. vera. A) Centro de división celular

(CD). B) Células meristemáticas en división (CM). C - D) Domo meristemático (DM) con protuberancias de primordios foliares (PF). E) ápice meristemático formado (AM), con primordios foliares (PF). F) yema adventicia (YA). Fuente: Autores.

Igualmente, fue evidente la multiplicación de células meristemáticas extendidas lateralmente a lo largo de la superficie del explante, mostrando una forma cóncava, rodeada por células parenquimatosas (figura 2B).

La formación de protuberancias con un mayor nivel de organización celular, dio origen al desarrollo de domos meristemáticos y primordios foliares en la región epidérmica (figura 2C-D). De la misma forma, se observó (figura 2D) desde el domo meristemático una banda de células hacia el interior del callo. El desarrollo de yemas adventicias y de primordios foliares, dieron origen a ápices meristemáticos, los cuales, a su vez, dieron origen a brotes diferenciados (figura 2E-F).

Proliferación de brotes regenerados. Los resultados de multiplicación de brotes obtenidos a partir de brotes individualizados producto de caulogénesis indirecta, mostraron que el medio con BA y ANA (mayor concentración de citoquinina y menor de auxina) fue efectivo para la producción de brotes axilares. 
En el primer ciclo de proliferación, el promedio de brotes/explante fue 6,0 y la longitud de los brotes fue 1,6 cm en promedio; mientras que en el segundo ciclo, se cuantificó un leve aumento del promedio de brotes/explante, 8,8 , y se mantuvo igual el promedio $(1,6)$ de longitud de los brotes respecto al primer ciclo de proliferación.

Enraizamiento ex vitro e in vitro. Al finalizar el enraizamiento ex vitro, se cuantificó $56,6 \%$ brotes enraizados en invernadero (tabla 3 ).
La media más baja de raíces desarrolladas por explante, se presentó en brotes enraizados ex vitro ( 0,7 raíces/explante). Los brotes presentaron raíces de $0,4 \mathrm{~cm}$ de longitud aproximadamente (tabla 3).

En el ensayo de enraizamiento in vitro, trascurridos 30 días de la transferencia de los brotes a medio para enraizamiento y sustrato sólido, se cuantificó un $75,3 \%$ de explantes enraizados (tabla 3).

Tabla 3. Enraizamiento de brotes ex vitro e in vitro

\begin{tabular}{cccc}
\hline Tratamiento & $\begin{array}{c}\text { Explantes enraizados } \\
(\%)\end{array}$ & $\begin{array}{c}\text { Longitud raíces } \\
(\bar{x})\end{array}$ & $\begin{array}{c}\text { Raíces/Explante } \\
(\bar{x})\end{array}$ \\
\hline Ex vitro & 56,6 & $0,4 \pm 0,5$ & $0,7 \pm 0,7 \mathrm{a}$ \\
In vitro & 75,3 & $1,5 \pm 1,2$ & $1,4 \pm 1,1 \mathrm{~b}$ \\
\hline
\end{tabular}

El análisis de varianza estableció diferencias estadísticamente significativas en cuanto a número de raíces presentes en brotes enraizados in vitro y ex vitro (Fc: 16,56; P: 0,0001); la media más alta se presentó en brotes enraizados bajo condiciones in vitro con (1,4 raíces/explante) (tabla 3). Los brotes enraizados presentaron raíces de longitudes significativamente diferentes según el análisis de varianza (Fc: 37,9; P: 0,0); e indicó que los brotes enraizados in vitro tienen la media más alta en longitud de raíces $(1,5 \mathrm{~cm}$, tabla 3$)$.

Aclimatización. Al cabo de 90 días, se cuantificó $95,3 \%$ de plántulas viables que reactivaron su crecimiento.

\section{DISCUSIÓN}

El alto porcentaje de asepsia superficial cuantificado en este estudio, coincide con los resultados observados por Sharifkhani et al. [15], quienes obtuvieron un 95,8 y $100 \%$ de explantes estériles de $A$. vera, luego de la aplicación de una solución de $\mathrm{NaOCl}$ durante 20 minutos a una concentración de 1,56\% y 2,25\%. El NaOCl es uno de los compuestos más utilizados para desinfección de tejidos vegetales $[16,17,18]$.

La morfogénesis hace referencia a la naturaleza y regulación de la expresión de la información genética que cada célula vegetal contiene y las rutas por las cuales dicha expresión es dirigida hacia el desarrollo de una forma organizada [19]. Las variaciones en las respuestas de desarrollo caulogénico adventicio observado en los diferentes tratamientos, se deben a que en los procesos de inducción morfogénica, las células son receptivas al estímulo morfogénico y hay una relación directa con el tipo, concentración y combinación de reguladores de crecimiento agregados al medio de cultivo y el órgano a desarrollar [20].

En los cultivos de ápices meristemáticos, el desarrollo rizogénico registrado en explantes cultivados en presencia de $1 \mathrm{mg} \mathrm{L}^{-1}$ de AIB y 1 y $3 \mathrm{mg} \mathrm{L}^{-1}$ de ANA, fue similar al de Sun et al. [21], quienes evidenciaron que la inducción de raíces adventicias en explantes de $A$. vera fue buena en todos los medios suplementados con ANA en concentraciones de $0,1,0,5$ y $1,0 \mathrm{mg} \mathrm{L}^{-1}$.

Los altos porcentajes de explantes con respuesta callogénica evidenciados en este estudio al utilizar 2,4-D, ANA, AIA y AIB, coinciden con los obtenidos por Sun et al. [21] y Matos y Sánchez [22]. Sun et al. [21], indujeron en hojas cultivadas en medio con 2,4-D, un callo de consistencia friable y evidenciaron que altas concentraciones de ANA $\left(2,0,4,0\right.$ y $\left.6,0 \mathrm{mg} \mathrm{L}^{-1}\right)$ también generaban un efecto similar. Mientras que Matos y Sánchez [22], obtuvieron un $40 \%$ de callos formados a partir de hojas, con una concentración de $2 \mathrm{mg}$ $\mathrm{L}^{-1}$ de AIA, en los tratamientos con AIB el mayor 
porcentaje, $25 \%$, se cuantificó en presencia de 3 mg L ${ }^{-1}$, mientras que con $1 \mathrm{mg} \mathrm{L}^{-1}$ la respuesta callogénica fue nula.

En este estudio, se evidenció que las citoquininas fueron menos efectivas para la estimulación callogénica de ápices meristemáticos; solo se observó formación de callos en presencia de $5 \mathrm{mg} \mathrm{L}^{-1}$ de 2 -iP. Dichos resultados contrastan con los obtenidos por Matos y Sánchez [22], quienes reportaron un $17 \%$ de formación de callos a partir de hojas cultivadas en medio con $1 \mathrm{mg} \mathrm{L}^{-1}$ de BA. Las mayores respuestas callogénicas a partir de discos caulinares se cuantificaron en los tratamientos suplementados con 2,4-D, AIA, ANA, 2,4-D+Kin y con AIB. Estos resultados coinciden con los obtenidos por Garro et al. [23], quienes indujeron callos a partir de tallos de $A$. barbadensis, con mayor frecuencia en MS con $0,25 \mathrm{mg} \mathrm{L}^{-1}$ de 2,4-D y $1 \mathrm{mg} \mathrm{L}^{-1}$ de Kin; aunque reportaron mejores resultados en medio suplementado con $2,5 \mathrm{mg} \mathrm{L}^{-1}$ de $2,4-\mathrm{D}$ y $2 \mathrm{mg} \mathrm{L}^{-1}$ de BA, similar a los resultados de Matos [24], quien reportó formación de callos en medio con $1 \mathrm{mg} \mathrm{L}^{-1}$ de 2,4 y $5 \mathrm{mg} \mathrm{L}^{-1}$ de BA, seguido por $0,5 \mathrm{mg} \mathrm{L}^{-1}$ de $2,4-\mathrm{D}$ y $0,1 \mathrm{mg}$ $\mathrm{L}^{-1}$ de kin. Igualmente, fueron obtenidos callos en segmentos nodales de $A$. vera en medio suplementado con $1 \mathrm{mg} \mathrm{L}^{-1}$ de 2,4-D y $0,2 \mathrm{mg}$ $\mathrm{L}^{-1}$ de Kin [25]. Mientras que con A. polyphylla fue reportada la formación de callo amarillento en la base de los brotes en medio con $1 \mathrm{mg} \mathrm{L}^{-1}$ de BA y $0,1 \mathrm{mg} \mathrm{L}^{-1}$ de ANA [26].

La baja regeneración de brotes adventicios observada a partir de callos puede ser debida a que las plantas de Aloe requieren cierto nivel interno de reguladores de crecimiento para que pueda ocurrir la regeneración. De igual forma, todas las diferencias encontradas en estos ensayos posiblemente se deben, a que la respuesta de un tejido al cultivo in vitro depende, en mayor medida, de la interacción entre el nivel hormonal endógeno y el tipo y concentración de los reguladores exógenos [27].

Asimismo, la fuente de explantes, su procedimiento de esterilización, la composición y condiciones de los medios de cultivo, la presencia de fenoles, el pardeamiento de los explantes por los fenoles y la decoloración de los medios de cultivo afectan en gran medida la regeneración de brotes de diferentes genotipos de la misma especie [28]. La formación diferencial de callo y producción de yemas axilares puede ser también explicada por la posición del explante a lo largo del tallo, en Solanum dolichosepalum por ejemplo, explantes cercanos al ápice formaron callo, yemas axilares y raíces más eficientemente que los más lejanos [18].

Por lo tanto, cada explante o un mismo explante, pero de diferente especie, responden de manera distinta a una misma concentración de reguladores de crecimiento, a causa de diferencias en el contenido hormonal endógeno [29]. Además, la formación de brotes en callos cultivados en medio con auxina sin citoquinina, se debe a que algunas especies de plantas tienen altos niveles de hormonas endógenas y no requieren cantidades extra de reguladores de crecimiento exógenos para que se lleven a cabo los procesos de regeneración [6].

Respecto al análisis histológico, la observación de domos meristemáticos desarrollados, de primordios foliares en la región epidérmica y de una banda de células hacia el interior del callo desde el domo meristemático; indican la formación de procámbium a partir del cual se formarán los futuros tejidos vasculares [30].

Al comparar los resultados obtenidos en este estudio con estudios realizados por otros autores con la misma especie o con especies del mismo género, se determinó que las causas por las cuales se presentan marcadas diferencias en el cultivo in vitro de esta especie son debidas, en gran parte al genotipo de las plantas madre, fuente de explantes; según Hosseini y Parsa [27] el $A$. vera es originario del África, y al distribuirse por algunas partes del mundo esta planta pudo tener un desarrollo diferente en cada región y subsecuentemente crecer y responder a condiciones adversas distintas.

Los resultados de multiplicación de brotes, mostraron que el medio con BA y ANA, fue efectivo para la producción de brotes axilares, concordando con Aggarwal [31], quien indica que para proliferación de brotes, los reguladores de crecimiento más utilizados son las citoquininas.

Varios autores han reportado que entre las citoquininas, el $\mathrm{BA}$ es el más efectivo para promover la formación de brotes. Esto contrasta 
con lo reportado por Hosseini y Parsa [27] para $A$. vera, quien obtuvo mejor proliferación en medio con Kin y con lo reportado por Ivanova y Van [32] para A. polyphylla con zeatina en lugar de BA. Por el contrario, existen reportes en los que el uso del BA, solo o en combinación con auxinas, promovió una mayor proliferación [6, $26,33,34,35,36,37]$.

Los resultados obtenidos sobre enraizamiento ex vitro, $56,6 \%$ de brotes enraizados en invernadero, contrastan con los obtenidos por Baksha et al. [6] quienes reportaron que las plántulas al ser trasferidas directamente a campo no sobrevivieron.

Aunque el promedio de raíces desarrolladas por explante, obtenido al finalizar el enraizamiento ex vitro fue bajo en comparación con el observado en condiciones in vitro, el inducir enraizamiento bajo condiciones ex vitro, tiene la ventaja que reduce los costos de la producción de plántulas con propósitos comerciales [31].

La diferencia entre enraizamiento in vitro y ex vitro se debe a que en condiciones in vitro la respuesta al enraizamiento de brotes es controlada por la composición del medio, las condiciones de cultivo, el genotipo y los reguladores de crecimiento [38, 39], siendo las auxinas las requeridas para inducción y formación de raíces [31]. Varios autores, han obtenido mejores resultados de enraizamiento con el uso de ANA, solo o en combinación [6, 33, 36, 37]; otros, registraron la mejor respuesta en presencia de AIB [26, 35], con AIA [7] y en medio libre de reguladores de crecimiento $[27,34]$.

Los altos porcentajes de viabilidad y reactivación del crecimiento de las plántulas, se deben a la alta capacidad que tienen para adaptarse a condiciones ex vitro sin mayor inconveniente, puesto que esta especie posee un metabolismo fotosintético ácido crasuláceo (CAM) y al pasar de la condición heterótrofa (in vitro) a autótrofa (ex vitro) desarrolla mayor resistencia a la pérdida de agua por excesiva transpiración, proceso reportado como una de las principales causas de muerte de vitro plantas en esta fase [40].

En conclusión, los ápices meristemáticos cultivados en medio con 5,0 $\mathrm{mg} \mathrm{L}^{-1}$ de ANA, son los explantes primarios más aconsejables para iniciar procesos organogénicos, la proliferación de brotes es efectiva en medio con $2 \mathrm{mg} \mathrm{L}^{-1}$ de BA y $0,1 \mathrm{mg} \mathrm{L}^{-1}$ de ANA y el enraizamiento es más favorable en condiciones ex vitro.

\section{REFERENCIAS}

[1] Faría G. 2002. "Desarrollo del cultivo "Aloe vera" (Aloe barbadensis Miller) como propuesta de desarrollo rural en el municipio Mara (estado Zulia, Venezuela)". Tesis de Doctorado, Facultad de filosofía y letras, Departamento de geografía y ordenación del territorio, Universidad de Zaragoza, Venezuela. p. 36.

[2] Serán T y Ahmad N. "Shoot organogenesis of Aloe plants with emphasis on TDZ". In: Thidiazuron: From urea derivative to plant growth regulator. Springer Nature, Singapore. 2018.

[3] Velásquez R y Imery J. "Fenología reproductiva y anatomía floral de las plantas Aloe vera y Aloe saponaria (Aloaceae) en Cumaná, Venezuela". Rev Biol Trop, vol. 6, no. 3, pp. 1109-1125, 2008.

[4] Kalimuthu K, Vijayakumar S, Senthilkumar R y Sureshkumar M. «Micropropagation of Aloe vera Linn - A medicinal plant». Int J. Biotech Biochem, vol. 6, no. 3, pp. 405-410, 2010.

[5] Sánchez A y Suárez E. «Morfo-anatomía de vitroplantas de zábila (Aloe vera $\mathrm{L}$. Burm.f.)». Rev Fac Agron (LUZ), vol. 28, no. 1, pp. 139-149, 2011.

[6] Baksha R, Jahan M, Khatun R y Munshi J. "Micropropagation of Aloe barbadensis Mill. Through in vitro culture of shoot tip explants". Plant Tissue Cult Biotech, vol. 15, pp. 121-126, 2005.

[7] Singh B y Sood N. «Significance of explant preparation and sizing in Aloe vera L. A highly efficient method for in vitro multiple shoot induction». Sci Hortic. HORTI-3268, pp. 1-6, 2009. 
[8] Martínez, M., Pacheco, J. y Solano, A. «Análisis de algunos factores que influyen en el proceso embriogénico en tejidos juveniles de Rubus glaucus Benth». Rev Asociación Colombiana Cien Biol, vol. 17, no. 1, pp. 95-107, 2005.

[9] Patel PM. "In vitro organogenesis of Aloe vera by shoot tip tissue culture method". Inventi Impact: Planta Activa, no. 1, pp. 196-212, 2013.

[10] Gui YL, Xu TY, Gu SR, Liu SQ, Zhang Z, Sun GD y Zhang Q. «Studies on stem tissue culture and organogenesis of Aloe vera". Acta Bot Sin, vol. 32, no. 8, pp. 606-610, 1990.

[11] Ahmed S, Kabir A.H. Ahmed M.B. Razvy M.A. y Ganesan S. "Development of rapid micropropagation method of Aloe vera L". Sjemenarstvo, vol. 24, no. 2, pp. 121-128, 2007.

[12] Lavakumaran L., y Seran T. "Effect of 6-benzyl-aminopurine and thidiazuron on in vitro shoot organogenesis of Aloe vera (L.)".Chilean J. Agric. Res, vol.74, no. 4, pp. 497-501, 2014.

[13] Gantait S., Sinniah U., y Kanti P. “Aloe vera: a review update on advancement of in vitro culture". Acta Agric. Scandinavica, vol. 64, no. 1, pp. 1-12, 2014.

[14] Murashige T y Skoog F. “A revised medium for rapid growth and bioassays with tabaco tissue cultures". Physiol Plantarum, vol. 15, pp. 473-493, 1962.

[15] Sharifkhani A, Mohd H y Bt Abd, M. "An alternative safer sterilization method for explants of Aloe vera barbadensis Mill". 2nd International Conference on Chemical Engineering and Applications, vol. 23, pp. 32-36, 2011.

[16] W. Roca y L. Mroginski. Cultivo de tejidos en la agricultura: fundamentos y aplicaciones. CIAT (centro Internacional de Agricultura Tropical). Ed. Cali. Colombia. 1991.
[17] S. Olmos, G. Luciani y E. Galdeano. "Parte V Métodos de propagación y conservación de germoplasma. Micropropagación". In: Biotecnología y Mejoramiento Vegetal II. G. Levitus, V. Echenique, C. Rubinstein, E. Hopps y L. Mroginski. Ediciones Instituto Nacional de Tecnología Agropecuaria, Argentina, pp. 161-172, 2004.

[18] Cárdenas-Burgos Camilo Andrés, PachecoMaldonado José C. y Vanzela André L. "Propagación in vitro de Solanum dolichosepalum (Solanaceae)". Ciencia en Desarrollo, vol. 7, no. 2, pp. 9-22, 2016.

[19] Osborne D. 1993. Morphogenic signals and markers in vitro and in vivo. En: $\mathrm{K}$. Roubelakis, A. Angelakis y K. Tran Thanh Van., Morphogenesis in plants. New York. Plenum Press. p. 19-57.

[20] Radice S. 2010. Morfogénesis: G. Levitus, V. Echenique, C. Rubinstein, E. Hopp y L. Mroginski., Biotecnología y Mejoramiento Vegetal II. Argentina. Ediciones Instituto Nacional de Tecnología Agropecuaria. p. 26-33.

[21] Sun Y, Yang T y Park S et al. "Induction and proliferation of adventitious roots from Aloe vera leaf tissues for in vitro production of aloe-emodin". Plant Omics Journal, vol. 4, no. 4, pp. 190-194, 2011.

[22] Matos A y Sánchez A. "Evaluación de reguladores de crecimiento para la inducción de callo en Aloe vera L". Multiciencias, vol. 11, no. 1, pp. 7-14, 2011.

[23] Garro G, Gatica A y Valdez M. «Somatic embryogenesis, plant regeneration and acemannan detection in Aloe (Aloe barbadensis MILL.)».Agron Costarricense, vol. 32, no. 2, pp. 41-52, 2008.

[24] Matos A. "Producción de Aloína en callos y hojas de brotes de Zábila (Aloe vera L.), regenerados in vitro". Bioagro, vol. 23, no. 2, pp. 79-86, 2011.

[25] Saggoo M y Kaur R. "Studies in North Indian Aloe vera: callus induction and 
regeneration of plantlets». Arch Apll Sci Res, vol. 2, no. 2, pp. 241-245, 2010.

[26] Abrie A y Staden J. «Micropropagation of the endangered Aloe polyphylla». Plant Growth Regul, vol. 33, pp. 19-23, 2001.

[27] Hosseini R, Parsa M. «Micropropagation of Aloe vera L. grown in south Iran». Pak $J$ Biol Sci, vol. 10, pp. 1134-1137, 2007.

[28] Nayanakantha N, Singh B y Kumar A. «Improved culture medium for micropropagation of Aloe vera L». Trop Agr Res Ext, vol. 13, no. 4, pp. 87-93, 2010.

[29] Marinucci L, Ruscitti M y Abediniet W. "Morfogénesis in vitro de leguminosas forestales nativas de la República Argentina”. Rev Facul Agron Plata, vol. 105, no. 2, pp. 27-36, 2004.

[30] Fuentes L y Alfonso Y. 2005. Aplicación de técnicas biotecnológicas en Stylosanthes guianensis (Aubl.) Sw., leguminosa forrajera promisoria para suelos infértiles. Monografía. p. 1-47

[31] Aggarwal D. 2003. Tissue culture of a medicinal plant-Aloe vera L. Patiala. Masters of Science in Biotechnology, Department of Biotechnology and Environmental Sciences, Thapar Institute of Engineering and Technology, Patiala. p. 53.

[32] Ivanova M y Van Staden J. "Influence of gelling agent and cytokinins on the control of hyperhydricity in Aloe polyphylla". Plant Cell Tiss Organ Cult, vol. 104, pp. 13-21, 2011.
[33] Liao Z, Chen M, Tan F, Sun X y Tang K. «Micropropagation of Chinese aloe». Plant Cell Tiss Org Cult, vol. 76, pp. 83-86, 2004.

[34] Aggarwal D y Barna K. «Tissue culture propagation of elite plant of Aloe vera Linn". J Plant Biochem Biotech, vol. 13, pp. 77-79, 2004.

[35] Supe U. "In vitro regeneration of Aloe barbadensis". Biotech, vol. 6, no. 4, pp. 601-603, 2007.

[36] Saroha V, Yadav R y Yadav N. «High frequency shoot regeneration in Aloe vera using BAP and TDZ combination of growth regulators". Recent Trends Horticultural Biotech, pp. 299-303, 2008.

[37] Hashemabadi D y Kaviani B. "Rapid micropropagation of Aloe vera L. via shoot multiplication". Afr J Biotech, vol. 7, no. 12, pp. 1899-1902, 2008.

[38] Rache L. y Pacheco J. "Establecimiento de un protocolo de propagación de Physalis peruviana $L$. a partir de yemas axilares adultas". Rev. Ciencia en Desarrollo, vol. 4, no. 1, pp. 71-86, 2012.

[39] López F., N. Guío, G. Fischer y Mirando, D. "Propagación de uchuva (Physalis peruviana L.) mediante diferentes tipos de esquejes y sustratos". Rev. Fac. Nal. Agro. Medellín, vol. 61, no. 1, pp. 4347-4357, 2008.

[40] Albany N, Vilchez J, León S, Molina M y Chacín P. "Una metodología para la propagación in vitro de Aloe vera L". Rev Fac Agron (LUZ), vol. 23, pp. 213-222, 2006. 